\title{
Microwave-Assisted Preparation of Biodegradable Water Absorbent Polyacrylonitrile/Montmorillonite Clay Nanocomposite
}

\author{
Prafulla K. Sahoo, Trinath Biswal, and Ramakanta Samal \\ Department of Chemistry, Utkal University, Vani Vihar, Bhubaneswar 751004, India \\ Correspondence should be addressed to Prafulla K. Sahoo, psahoochemuu@satyam.net.in \\ Received 3 December 2010; Revised 25 March 2011; Accepted 28 March 2011 \\ Academic Editor: Baoquan Sun
}

Copyright ( $) 2011$ Prafulla K. Sahoo et al. This is an open access article distributed under the Creative Commons Attribution License, which permits unrestricted use, distribution, and reproduction in any medium, provided the original work is properly cited.

Polyacrylonitrile (PAN)/Montmorillonite (MMT) clay nanocomposite was prepared in a microwave oven using a transition metal Co(III) complex taking ammonium persulfate (APS) as initiator with a motive of converting hydrophobic PAN into hydrophilic nanocomposite material via nanotechnology by the inclusion of MMT to the virgin polymer. UV-visible spectral analysis revealed various interactions between the developed complex with other reaction components. The formation of the PAN/MMT nanocomposites was characterized by FTIR. Furthermore, as evidenced by X-ray diffraction (XRD), transmission electron microscopy (TEM), the composite so obtained was found to have nano-order. XRD and TEM were suggesting that montmorillonite layers were exfoliated during the polymerization process. An increasing in the thermal stability for the developed nanocomposite was recorded by thermogravimetric analysis (TGA). The water absorption and biodegradation properties were carried out for its ecofriendly nature and better commercialization.

\section{Introduction}

A great deal of research on organic polymer-layered silicate nanocomposites have been carried out over the past decade due to their substantial enhanced physical properties over virgin polymers, even when prepared with a very small amount of layered silicate $[1,2]$. These nanocomposites, especially polymer-layered silicate nanocomposites (PLSNs), are emerging as the most significant and new breed of composite materials due to their extensively enhanced mechanical [3], thermal [4] flammability $[5,6]$ properties. These unique properties of nanocomposites arise from the maximized contact between the organic and inorganic phase, so fillers with high surface-to-volume ratio are commonly used. Layered silicates such as MMT, which are composed of stacks of parallel lamellae with a $1 \mathrm{~nm}$ thickness and a high aspect ratio, are typically used.

Unlike to a virgin polymer or conventional micro and macro composites, the improvement in properties of PLSNs is remarkable, including high moduli [7], increased strength and heat resistance [8], decreased gas permeability [9] and flammability [10], and increased biodegradability [11]. Following to this, there has been considerable interest in theory and simulations addressing the preparation, characterization, and properties of these materials [12], and they are also considered to be the structure and dynamics of polymers in confined environments [13].

Microwave heating is rapidly developing as an alternative to conventional heating techniques used in thermally initiated polymerization. The interaction between the microwave energy and molecular dipole moments of the starting materials provides an effective, selective, clean, and fast synthetic method [14]. However, although many benefits of microwave radiation have been recognized, the use of this radiation in polymer chemistry is still rather unexplored. Microwave radiation may be used as an alternative to thermal polymerization processes [15]. The advantages of microwaves are increased rate of production, improved product characteristics, uniform processing, less processes [16]. There are reports [17-19] that show similar kinetics 
under both microwave and thermal methods, indicating that microwave does not alter the reaction products observed in conventional heating, but up to three fold increase in magnitude.

Further, study on green polymeric materials which avoid the use of any toxic or noxious components in their manufacture and could be naturally biodegradable, are in demand, as they reduce the hazardous effect of plastics and other polymeric compounds on environment. So far, biodegradable polymers, such as polylactide (PLA) [20, 21], polyhydroxy butyrate [22], aliphatic polyester [23, 24], and so forth, are mostly used for the preparation of nanocomposites; however, no report has been published regarding biodegradability and water absorbency of PLSNs. So in the present study, an attempt has been taken to highlight these aspects and to prepare PAN/MMT nanocomposites via a nonconventional microwave irradiation method in the absence of surfactant or emulsifier under the catalytic effect of transition metal complex $\left[\mathrm{Co}(\mathrm{III})(\mathrm{en})_{2}\left(\mathrm{NO}_{2}\right)_{2}\right] \mathrm{NO}_{3}$. Nonconventional method of synthesis of various polymers under the catalytic effect of complex of transition metals have already been reported $[12,25]$ in our earlier publications. Thus the most significant outcome of the paper is the preparation of the nonbiodegradable hydrophobic PAN into the biodegradable hydrophilic material by microwave irradiation via the application of nanotechnology. PAN/MMT nanocomposites so obtained were found to be biodegradable and exhibited significant waterabsorbency.

\section{Experimental}

2.1. Materials. Monomer, AN E merck India, was purified as reported earlier [26]. The initiator, APS, and all other reagents like Cobalt (II) Chloride, ethylene diamine (en) and so forth, were from $\mathrm{E}$ merck India (AR grade) and were used after purification by standard techniques. Na-MMT clay with cation exchange capacity (CEC) of 90 -mequiv/100 g was from Himedia India Ltd.

2.2. Preparation of $\left[\mathrm{Co}(\mathrm{III}) \mathrm{en}_{2}\left(\mathrm{NO}_{2}\right)_{2}\right] \mathrm{NO}_{3}$ Complex. A mixture of $6.85 \mathrm{~g}$ of $70 \%$ ethylene diamine (en) $(0.08 \mathrm{moL})$ and $10 \mathrm{ml}$ of water was partially neutralized by the addition of $3 \mathrm{ml}$ of concentrated nitric acid $(0.048 \mathrm{moL})$. The resulting solution was added to a solution of $11.5 \mathrm{~g}$ of $\mathrm{Co}\left(\mathrm{NO}_{3}\right)_{2}$ $6 \mathrm{H}_{2} \mathrm{O}(0.04 \mathrm{moL})$ and $6 \mathrm{~g}$ of sodium nitrite $(0.087 \mathrm{moL})$ in $20 \mathrm{ml}$ water. A vigorous stream of air was passed through the solution. The yellow trans- $\left[\mathrm{Co}(\mathrm{III}) \mathrm{en}_{2}\left(\mathrm{NO}_{2}\right)_{2}\right] \mathrm{NO}_{3}$ began to precipitate after 20 minutes. The mixture was cooled in an ice bath and filtered. The yellow crystalline solid was recrystallised from boiling water, washed with alcohol and ether and air dried. The formation of the complex trans-[Co(III)en $\left.\mathrm{en}_{2}\left(\mathrm{NO}_{2}\right)_{2}\right] \mathrm{NO}_{3}$ was confirmed by UV-visible spectral analysis (Scheme 1).

2.3. Synthesis of PAN Nanocomposites by Microwave Oven. The polymerization experiments were carried out in a Kenstar (Model No. MOW 9811, 1200 W) domestic MW oven. The average bulk temperature at end of the reaction was measured by inserting a thermometer in the reaction mixture. All the experiments were done with water and benzene as solvent, and the temperature is less than $100^{\circ} \mathrm{C}$. The polymerization experiment was carried out first in two parts. The first part was carried out in reaction vessel containing the requisite amount $(0.1 \mathrm{M})$ of each trans$\left[\mathrm{Co}(\mathrm{III}) \mathrm{en}_{2}\left(\mathrm{NO}_{2}\right)_{2}\right] \mathrm{NO}_{3}$ with a known amount of $\mathrm{AN}$ in 4/5th part deionized water. At the same time, desired amount of MMT was dispersed in rest $1 / 5$ th part of water at same condition. The MMT suspension was added to the reaction vessel and stirred with constant velocity at $\mathrm{N}_{2}$ atmospheric pressure. Then requisite amount of initiator solution was carefully injected to the reaction mixture. For all the MW power studies, the exposure time was varied from 30 to $180 \mathrm{sec}$. After completing reaction, the polymerization was terminated by the addition of a $0.1 \mathrm{M}$ solution of ferrous ammonium sulfate solution. The coagulated products were purified. The variations of different components along with conversions were tabulated in Table 1.

\subsection{Characterization}

2.4.1. Infrared Spectra (FTIR). The IR spectra of PAN and PAN/MMT nanocomposite, in the form of $\mathrm{KBr}$ pellets, were recorded with a Perkin-Elmer model Paragon-500 FTIR spectrophotometer.

2.4.2. X-Ray Diffraction (XRD). The incorporation of NaMMT into the matrix was confirmed by using an XRD monitoring diffraction angle $2 \theta$ from $1.5^{\circ}$ to $10^{\circ}$ on a Philips PW-1847 X-ray crystallographic unit equipped with Guinier focusing camera with Cuk radiation $(+0.1505 \mathrm{~nm})$ with a $0.02 \mathrm{~s}$ step size and a 2.5 count time.

2.4.3. Transmission Electron Microscopy (TEM). Nanoscale structure of PAN/MMT was investigated by means of TEM (H-700, Hitachi Co.), operated at an accelerating voltage of $100 \mathrm{kV}$. The ultrathin section (the edge of the sample sheet perpendicular to the compression mold) by diamond knife with a thickness of $100 \mathrm{~nm}$ was microtomed at $-80^{\circ} \mathrm{C}$.

2.4.4. Scanning Electron Microscopy (SEM). The surface morphology of PAN/MMT nanocomposite before and after biodegradation was studied by scanning electron microscopy (SEM) using Jeol Ltd, Japan and Model 5200 scanning electron microscope.

2.4.5. Mechanical Properties. Tensile bars were obtained on a Van Dorn 55 HPS 2.8F mini injection molding machine under the following processing conditions: a melt temperature of $150^{\circ} \mathrm{C}$, a mold temperature of $25^{\circ} \mathrm{C}$, an injection speed of $40 \mathrm{~mm} / \mathrm{s}$, an injection pressure of $10 \mathrm{MPa}$, and a holding time of $2 \mathrm{~s}$, with a total cycle time of $30 \mathrm{~s}$. Tensile measurements on injection molded samples of nanocomposites were performed according to ASTM D-63800 using an Instron test machine Model 5567. Tests were carried out at a crosshead speed of $50 \mathrm{~mm} / \mathrm{min}$ and a $1 \mathrm{kN}$ load cell without the use of an extensometer. All tests were 


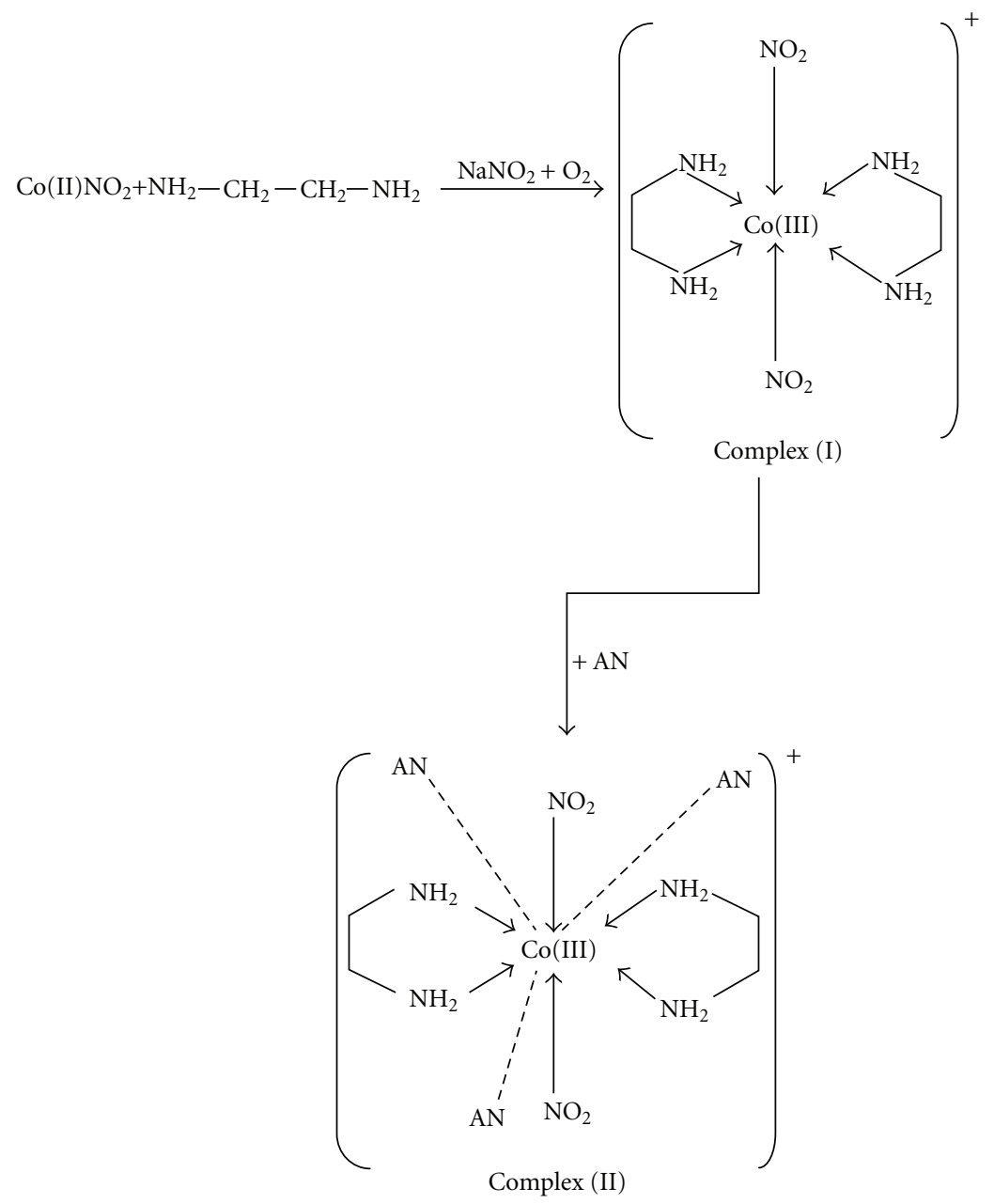

Scheme 1: Schematic representation of $\left[\mathrm{Co}(\mathrm{III})(\mathrm{en})_{2}\left(\mathrm{NO}_{2}\right)_{2}\right] \mathrm{NO}_{3}$ complex (I), (b) coordination of monomer AN with [Co(III)(en) 2 . $\left.\left(\mathrm{NO}_{2}\right)_{2}\right] \mathrm{NO}_{3}$ complex (II).

performed at room temperature and the results were the average of five measurements. The highest value of standard deviation was $15 \%$.

2.4.6. Thermogravimetric Analysis (TGA). Thermal properties were measured by using Shimadzu DTA-500 system in air, from room temperature to $600^{\circ} \mathrm{C}$ at a heating rate of $10^{\circ} \mathrm{C}$ per min.

2.4.7. UV-Visible Spectral Analysis. The UV-visible spectra of $\left[\mathrm{Co}(\mathrm{III}) \mathrm{en}_{2}\left(\mathrm{NO}_{2}\right)_{2}\right] \mathrm{NO}_{3}$ complex vis-à-vis those of the monomer and the initiator were studied using a Perkin Elmer UV-visible spectrophotometer model Lambda-20.

2.4.8. Water Absorbency. One gram each of the powdered sample (PAN, PAN/MMT) was palatalized by using 10 tons of pressure of around $0.05 \mathrm{~cm}$ of thickness and $1.5 \mathrm{~cm}$ of diameter. The pellet was then immersed in water at room temperature until equilibrium was reached. The water absorption was determined by weighing the swollen pellet after it had been wrapped between the folds of filter paper. The water absorbency [27] $Q\left(\mathrm{~g} \mathrm{H}_{2} \mathrm{O} / \mathrm{g}\right.$ sample) was calculated by using the equation: $\mathrm{Q}\left(\mathrm{g} \mathrm{H}_{2} \mathrm{O} / \mathrm{g}\right.$ sample $)=$ $\left(m-m_{0}\right) / m_{0}$, where $m$ and $m_{0}$ were denoted by weight of the samples swollen by water and dried weight of the sample, respectively.

\subsection{Biodegradation}

2.5.1. By Activated Sludge. In the present work, the activated sludge water was collected [28] in a polypropylene container from a tank area receiving toilet and domestic waste water. The container was filled completely and fully closed. The waste water was then brought to the laboratory immediately. After settling for $1 \mathrm{~h}$, the total solid concentration was increased to $5000 \mathrm{mg} / \mathrm{L}$. The activated sludge water and a polymer sample $(0.2 \mathrm{~g})$ were incubated together in a sterilized vessel at room temperature $(28 \pm$ $2^{\circ} \mathrm{C}$ ). Duplicate samples were removed at time intervals for biodegradation study via weight loss. Vessels containing polymer samples without sludge water were treated as controls. 
TABLE 1: Effect of variation of concentration of AN, APS, Co(III) complex, MMT, and time on the \% of conversion and water absorbency.

\begin{tabular}{|c|c|c|c|c|c|c|c|}
\hline Sample code & $\begin{array}{c}(\mathrm{AN}) \\
\mathrm{moL} \cdot \mathrm{dm}^{-3}\end{array}$ & $\begin{array}{l}(\mathrm{APS}) \times 10^{2} \\
\mathrm{MoL} \cdot \mathrm{dm}^{-3}\end{array}$ & $\begin{array}{c}(\text { Complex }) \times \\
10^{2} \text { moL } \times \\
\mathrm{dm}^{-3} \\
\end{array}$ & $\begin{array}{c}(\mathrm{MMT}) \\
\mathrm{moL} \times \mathrm{dm}^{-3}\end{array}$ & Time in Sec & $\%$ conversion & $\begin{array}{c}\text { Water } \\
\text { absorbency } Q\end{array}$ \\
\hline $\mathrm{S}_{0}$ & 7.0 & 2.0 & 2.0 & 0.0 & 180 & 55.45 & 09 \\
\hline$S_{1}$ & 0.38 & 2.0 & 2.0 & 5.0 & 180 & 57.19 & 39 \\
\hline $\mathrm{S}_{2}$ & 0.76 & 2.0 & 2.0 & 5.0 & 180 & 64.08 & 42 \\
\hline $\mathrm{S}_{3}$ & 1.51 & 2.0 & 2.0 & 5.0 & 180 & 68.85 & 74 \\
\hline $\mathrm{S}_{4}$ & 2.27 & 2.0 & 2.0 & 5.0 & 180 & 79.06 & 87 \\
\hline $\mathrm{S}_{5}$ & 3.03 & 2.0 & 2.0 & 5.0 & 180 & 64.45 & 68 \\
\hline $\mathrm{S}_{6}$ & 3.79 & 2.0 & 2.0 & 5.0 & 180 & 58.43 & 59 \\
\hline $\mathrm{S}_{7}$ & 4.55 & 2.0 & 2.0 & 5.0 & 180 & 54.57 & 56 \\
\hline $\mathrm{S}_{8}$ & 2.27 & 0.5 & 2.0 & 5.0 & 180 & 25.05 & 56 \\
\hline $\mathrm{S}_{9}$ & 2.27 & 1.0 & 2.0 & 5.0 & 180 & 58.18 & 69 \\
\hline$S_{10}$ & 2.27 & 1.5 & 2.0 & 5.0 & 180 & 72.65 & 75 \\
\hline$S_{11}$ & 2.27 & 2.0 & 2.0 & 5.0 & 180 & 79.06 & 87 \\
\hline$S_{12}$ & 2.27 & 2.5 & 2.0 & 5.0 & 180 & 68.06 & 79 \\
\hline $\mathrm{S}_{13}$ & 2.27 & 3.0 & 2.0 & 5.0 & 180 & 54.49 & 72 \\
\hline $\mathrm{S}_{14}$ & 2.27 & 3.5 & 2.0 & 5.0 & 180 & 48.56 & 64 \\
\hline$S_{15}$ & 2.27 & 2.0 & 0.5 & 5.0 & 180 & 35.09 & 69 \\
\hline$S_{16}$ & 2.27 & 2.0 & 1.0 & 5.0 & 180 & 54.54 & 77 \\
\hline$S_{17}$ & 2.27 & 2.0 & 1.5 & 5.0 & 180 & 68.89 & 83 \\
\hline$S_{18}$ & 2.27 & 2.0 & 2.0 & 5.0 & 180 & 79.06 & 87 \\
\hline$S_{19}$ & 2.27 & 2.0 & 2.5 & 5.0 & 180 & 64.00 & 76 \\
\hline $\mathrm{S}_{20}$ & 2.27 & 2.0 & 3.0 & 5.0 & 180 & 56.75 & 69 \\
\hline$S_{21}$ & 2.27 & 2.0 & 3.5 & 5.0 & 180 & 48.95 & 62 \\
\hline $\mathrm{S}_{22}$ & 2.27 & 2.0 & 2.0 & 1.25 & 180 & 53.41 & 65 \\
\hline $\mathrm{S}_{23}$ & 2.27 & 2.0 & 2.0 & 2.5 & 180 & 62.31 & 76 \\
\hline $\mathrm{S}_{24}$ & 2.27 & 2.0 & 2.0 & 5.0 & 180 & 79.06 & 87 \\
\hline $\mathrm{S}_{25}$ & 2.27 & 2.0 & 2.0 & 10 & 180 & 72.55 & 84 \\
\hline$S_{26}$ & 2.27 & 2.0 & 2.0 & 15 & 180 & 69.06 & 80 \\
\hline $\mathrm{S}_{27}$ & 2.27 & 2.0 & 2.0 & 20 & 180 & 63.07 & 76 \\
\hline $\mathrm{S}_{28}$ & 2.27 & 2.0 & 2.0 & 25 & 180 & 56.08 & 73 \\
\hline $\mathrm{S}_{29}$ & 2.27 & 2.0 & 2.0 & 5.0 & 60 & 57.09 & \\
\hline $\mathrm{S}_{30}$ & 2.27 & 2.0 & 2.0 & 5.0 & 90 & 65.59 & \\
\hline$S_{31}$ & 2.27 & 2.0 & 2.0 & 5.0 & 120 & 69.49 & \\
\hline$S_{32}$ & 2.27 & 2.0 & 2.0 & 5.0 & 150 & 74.55 & \\
\hline$S_{33}$ & 2.27 & 2.0 & 2.0 & 5.0 & 180 & 79.06 & \\
\hline $\mathrm{S}_{34}$ & 2.27 & 2.0 & 2.0 & 5.0 & 210 & 79.57 & \\
\hline $\mathrm{S}_{35}$ & 2.27 & 2.0 & 2.0 & 5.0 & 240 & 79.65 & \\
\hline $\mathrm{S}_{36}$ & 2.27 & 2.0 & 2.0 & 5.0 & 300 & 79.75 & \\
\hline
\end{tabular}

2.5.2. In Cultured Medium. A cultured medium was prepared by taking nutrient broth. In that medium, Bacillus cereus (gram-positive stain) was inoculated separately. The pure cultures were maintained separately in the incubator. The nutrient broth so prepared was sterilized for $45 \mathrm{~m}$ at a pressure of $15 \mathrm{lb} / \mathrm{in}^{2}$ at $80^{\circ} \mathrm{C}$. Then to $10 \mathrm{ml}$ of sterilized broth $0.1 \mathrm{~g}$, each of the samples, that is, PAN, PAN/MMT nanocomposites were added aseptically in separate test tubes, and each tube of samples were supplemented with inoculum of different bacterial stains separately.

The degradation of samples by $B$. cereus was monitored in time intervals of $1,7,15$, and 30 days. After the required time period, the samples were washed repeatedly with deionised water, oven dried at $40 \pm 1^{\circ} \mathrm{C}$ for $24 \mathrm{~h}$. Then the samples were weighed to determine the weight loss. Biodegradation through $B$. cereus was studied by the amount of $\mathrm{CO}_{2}$ evolved 


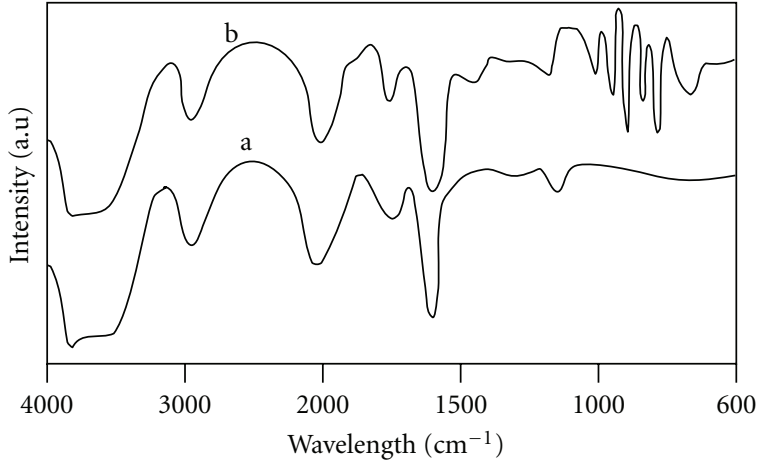

FIgURE 1: FTIR spectra of (a) PAN and (b) PAN/MMT (5\%w/v) nanocomposite.

[29] during the incubation periods of $1,7,15$, and 30 days.

\subsubsection{Quantitative Estimation of Free $\mathrm{CO}_{2}$}

Chemicals Requirement. $\mathrm{Na}_{2} \mathrm{CO}_{3}$, phenolphthalein indicator.

Procedure 1. The cultured sample (" $X$ " $\mathrm{ml}$ ) and blank tube were titrated against $\mathrm{Na}_{2} \mathrm{CO}_{3}$ (N/50)-(“ $Y$ ” ml) using phenolphthalein indicator until the pink color persists for at least $30 \mathrm{~s}$. This was continued till getting a concordant reading.

\section{Calculation}

$$
\begin{aligned}
\mathrm{N}_{1} \mathrm{~V}_{1}=\mathrm{N}_{2} \mathrm{~V}_{2} & \\
\left(\mathrm{CO}_{2}\right) \quad\left(\mathrm{Na}_{2} \mathrm{CO}_{3}\right) & =\left(\frac{1}{50}\right) \times Y \\
\Rightarrow \mathrm{N}_{1} \times X \quad & =\frac{(Y \times 22)}{(50 \times X)} \\
\Rightarrow \text { Strength } & \left(\frac{(Y \times 22 \times 1000)}{(50 \times X)}\right) \mathrm{mg} / \mathrm{l} \\
\Longrightarrow \text { Free } \mathrm{CO}_{2}= & \left(\frac{(440 \times Y)}{X}\right) \mathrm{ppm} .
\end{aligned}
$$

\section{Results and Discussion}

From the series of experiments, it was found that the PAN was intercalated into gallery structure of silicate by the catalytic action of $\left[\mathrm{Co}(\mathrm{III})(\mathrm{en})_{2}\left(\mathrm{NO}_{2}\right)_{2}\right] \mathrm{NO}_{3}$ complex. The complex initiating system helps to stabilize the emulsion latex to a high conversion level in the absence of added emulsifier (Table 1). The initiation is a surface catalysis with adequate energy transfer from the complex to the initiator (APS), resulting in a complex initiation mechanism deviating from a simple path of decomposition. The concerted

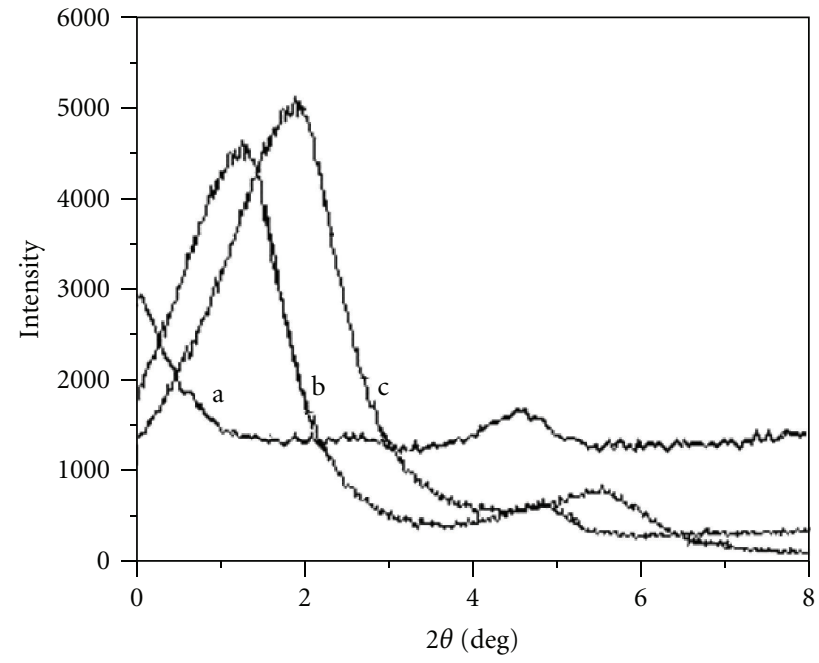

FIGURE 2: XRD of PAN/MMT nanocomposites (a) 5\%, (b) $10 \% \mathrm{w} / \mathrm{v}$, and (c) pure MMT clay.

generation-consumption criterion is the driving force in the complex-catalyzed peroxide and vinyl polymerization [30].

3.1. FTIR. Absorption peaks for PAN, PAN/MMT nanocomposite are shown in Figures 1(a) and (b). The absorption peak at $1079 \mathrm{~cm}^{-1}$ is due to the $\mathrm{Si}-\mathrm{O}-\mathrm{Si}$ linkage (Figure $1(\mathrm{~b})$ ). The peak at $1360 \mathrm{~cm}^{-1}$ is due to $=\mathrm{CH}_{2}$ bending, and $1453 \mathrm{~cm}^{-1}$ is due to the scissoring vibration of terminal methylene group. The stretching vibration of $-\mathrm{C} \equiv \mathrm{N}$ and vinyl $\mathrm{C}-\mathrm{H}$ of the composite showed peak at $2245 \mathrm{~cm}^{-1}$ and $2935 \mathrm{~cm}^{-1}$, respectively. The peak at $2956 \mathrm{~cm}^{-1}$ is due to antisymmetric $>\mathrm{CH}_{2}$ stretching. The IR spectra of PAN/MMT (Figure 1(b)) contain all the peaks of both silicate and PAN. Thus, the comparative spectral peaks revealed the formation of PAN/MMT nanocomposite as confirmed further by subsequent studies, XRD, TEM.

3.2. XRD Analysis. XRD has been used to evaluate the degree of interaction of the layered silicates with the polymer matrix. The systematic arrangement of the silicate layers of the intercalated composites has been elucidated by XRD in calculating interlayer spacing with the help of Bragg's equation. Figure 2 shows the XRD diffraction pattern of MMT and PAN/MMT nanocomposite. The MMT layers are exfoliated when MMT $\leq 5 \%$ as indicated by the disappearance of any peak Figure $2(\mathrm{a})$, but when MMT $\geq 10 \%$, it gives intercalated nanocomposites as shown in Figure 2(b) which were further conformed from TEM (Figure 3). Further, the XRD patterns suggest that the hydrophobic PAN is inserted into the galleries of the hydrophilic silicate through emulsion polymerization, and that the disordered insertion of the polymer into hydrophilic silicate layers made the nanocomposite partially hydrophilic in nature.

3.3. TEM Analysis. The internal structure of PAN/MMT nanocomposite was further conformed by TEM Figure 3, which directly visualized the expanded layering structure in 


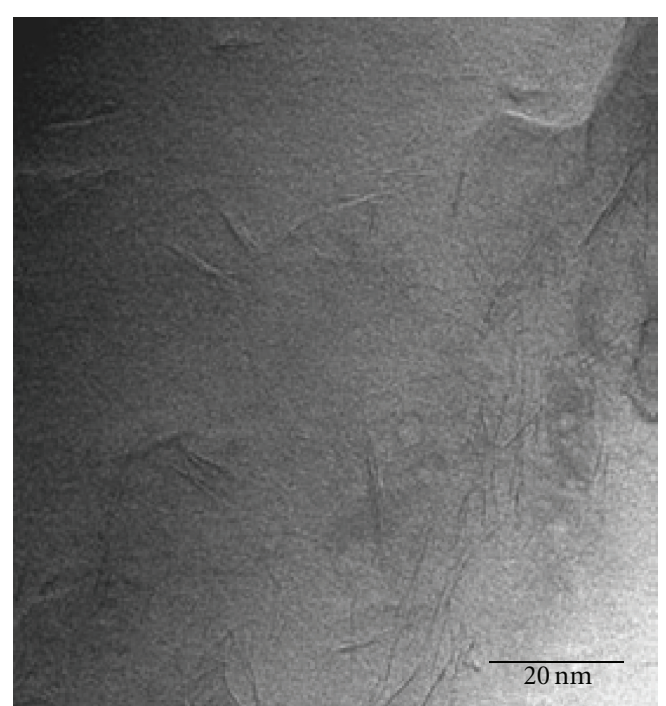

(a)

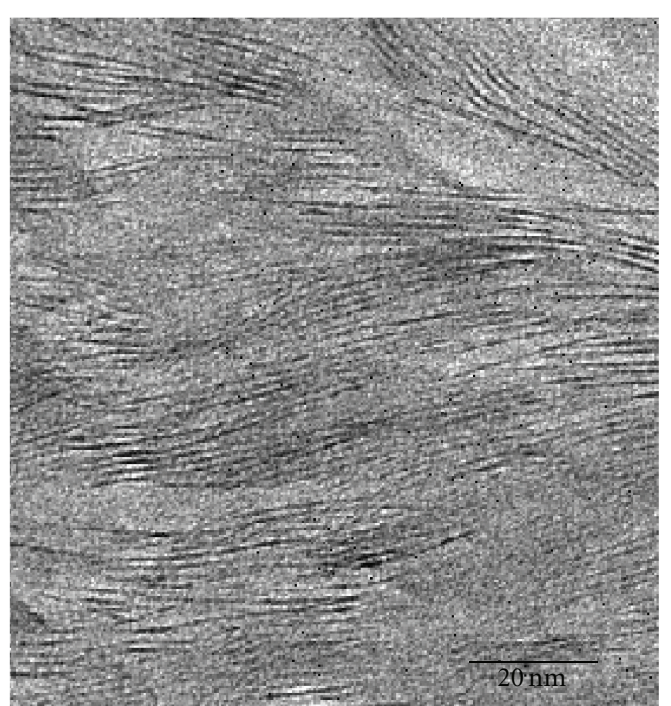

(b)

FIgURE 3: TEM micrographs of PAN/MMT nanocomposites (a) 5\% and (b) $10 \% \mathrm{w} / \mathrm{v}$.

the nanocomposites and partial dispersion of silicate layers in polymer matrix [31]. Figure 3(a) demonstrated a mixed nanostructure with well-dispersed layers of polymer blend nanocomposites showing compatibility between PAN and silicate. The interlayer spacing in the figure reveals the intercalation of PAN matrix with silicate layers [32] as evidenced by XRD. Figure 3(b) gives the TEM of nanocomposite after combustion which is in agreement with the result obtained in XRD study.

3.4. Thermal Analysis. The thermal properties of the nanocomposite materials have been evaluated by TGA as shown in Figure 4. In contrast to PAN, the onset of decomposition for PAN/MMT nanocomposite is shifted towards a higher temperature with inclusion of MMT, indicating an enhancement of the thermal stability upon intercalation. The PNA/MMT nanocomposite exhibited higher thermal stability due to the higher decomposition onset temperature than that of PAN, which can be attributed to the nanoscale silicate layers preventing outdiffusion of the volatile decomposition product. On the other hand, since the inorganic part (silicate) of the nanocomposite film almost did not lose its weight during the heating period, the shift of weight loss to higher-temperature region might be simply due to that the nanocomposite films possessed relatively small amount (about $4 \mathrm{wt} \%$ ) of organic polymer that contributed to the weight loss. The higher thermal stability of PAN/MMT nanocomposite suggests that the generated silica-rich char is protecting the polymer from ambient oxygen, and reducing the rate of oxidative degradation in the nanocomposite materials [33] than that of PAN, which can be attributed to the nanoscale clay layers preventing outdiffusion of the volatile decomposition product. On the other hand, the inorganic part of the nanocomposite film almost did not lose its weight during the heating period.

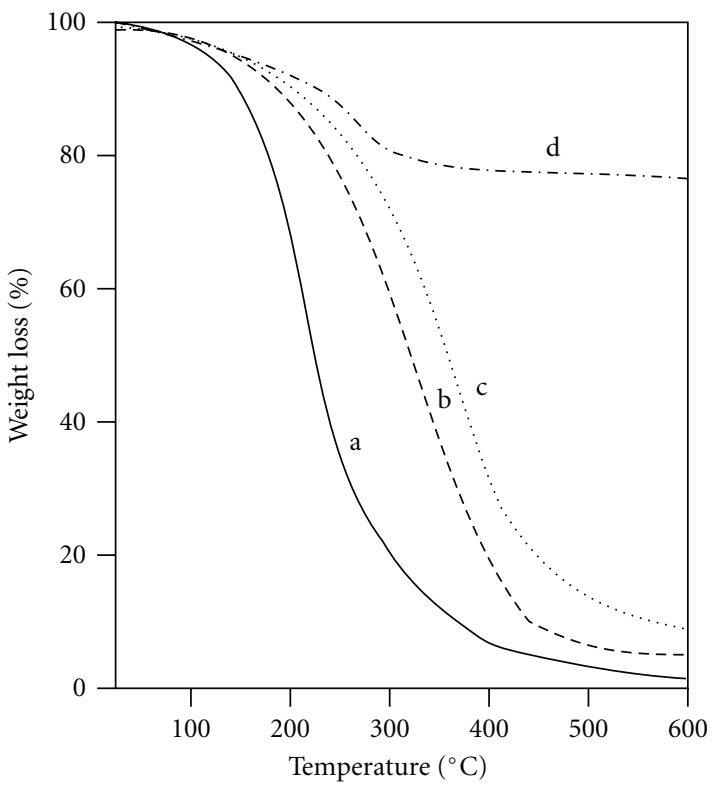

Figure 4: TGA of (a) PAN, (b) PAN/MMT (5\%w/v) nanocomposite, (c) PAN/MMT (10\%w/v) nanocomposite, and (d) MMT Clay.

3.5. Mechanical Properties. The mechanical properties, including Young's modulus, elongation at break, toughness, yield stress, and yield strain of all the nanocomposites prepared in this study, together with the corresponding values of the virgin polymer, are given in Table 2 . The significant increase in the Young's modulus of nanocomposites with increase of silicate concentration is due to the slight possibility of hydrogen bonding between the nitrile groups of AN and large number of hydroxyl $(\mathrm{OH})$ groups present on the surface of the clay layers [34], where as the yield 
TABLE 2: Comparative data of mechanical properties ( \pm error point) of PAN and PAN/MMT nanocomposites.

\begin{tabular}{lccccc}
\hline Sample code & Young's model. $(\mathrm{MPa})$ & Elong. at break $(\%)$ & Toughness, $(\mathrm{MPa})$ & Yield strain $(\%)$ & Yield stress $(\mathrm{MPa})$ \\
\hline $\mathrm{S}_{0}$ & $218 \pm 11$ & $708 \pm 40$ & $142.6 \pm 17$ & $24.8 \pm 1.9$ & $18.1 \pm 1.6$ \\
$\mathrm{~S}_{22}$ & $264 \pm 13$ & $659 \pm 29$ & $84.5 \pm 34$ & $23.6 \pm 2.0$ & $17.6 \pm 1.2$ \\
$\mathrm{~S}_{24}$ & $365 \pm 12$ & $578 \pm 32$ & $52.1 \pm 29$ & $22.1 \pm 1.6$ & $17.4 \pm 1.6$ \\
$\mathrm{~S}_{25}$ & $382 \pm 17$ & $493 \pm 28$ & $33.5 \pm 15$ & $21.8 \pm 1.5$ & $16.6 \pm 1.8$ \\
$\mathrm{~S}_{27}$ & $413 \pm 23$ & $367 \pm 19$ & $20.4 \pm 12$ & $20.2 \pm 0.9$ & $15.8 \pm 1.4$ \\
\hline
\end{tabular}

stress and strain decreased monotonically with increase of MMT content. Due to their rigidity, MMT particles cannot be deformed by external stress in the specimen but act only as stress concentrators during deformation process [35]. Elongation at break and toughness of nanocomposites decreased tremendously with increasing MMT content which is in accordance with the results obtained earlier [36]. Therefore, emulsion process played a vital role in the dispersion of MMT in PAN, creating a strong interfacial adhesion with the matrix.

The results of the study on the polymerization of $\mathrm{AN}$ initiated by APS catalyzed by, $\left[\mathrm{Co}(\mathrm{III})(\mathrm{en})_{2}\left(\mathrm{NO}_{2}\right)_{2}\right] \mathrm{NO}_{3}$ were tabulated in Table 1. From the results, it is evident that the maximum rate of polymerization and the order of $R_{p}$ for various systems are as follows:

$$
R_{p}\left(\mathrm{APS}+\left[\mathrm{Co}(\mathrm{III})(\mathrm{en})_{2}\left(\mathrm{NO}_{2}\right)_{2}\right] \mathrm{NO}_{3}\right)>R_{p}(\mathrm{APS})
$$

3.6. UV-Visible. The UV-visible spectra of various mixtures like $\left[\mathrm{Co}(\mathrm{III})(\mathrm{en})_{2}\left(\mathrm{NO}_{2}\right)_{2}\right] \mathrm{NO}_{3},\left[\mathrm{Co}(\mathrm{III})(\mathrm{en})_{2}\left(\mathrm{NO}_{2}\right)_{2}\right]$. $\mathrm{NO}_{3} / \mathrm{APS}$, and $\left[\mathrm{Co}(\mathrm{III})(\mathrm{en})_{2}\left(\mathrm{NO}_{2}\right)_{2}\right] \mathrm{NO}_{3} /$ AN/APS before reaction and after reaction were measured in an aqueous solution to obtain a complete picture of the interaction between the reacting species and their relationship with the rate data (Figure 5). The bidentate ligand character of en with colored cations like $\mathrm{Co}(\mathrm{II})$ to form chelate complex is well recognized [37], where the Co(III)-en ratio in complex Scheme $1(\mathrm{a})$ is $1: 2$ as evidenced by the proportionality found in the rate expression. Further, the central metal ion, $\mathrm{Co}(\mathrm{III})$ is coordinated to three molecules of monomer (AN), (Complex-II, Scheme 1(b)) as revealed from the sharp change in absorbance from 1.3 (b) to 1.2 (c) in Figure 5 which is also accorded from the rate expression. On addition of the initiator (APS), to the above mixture (Complex-II), the absorbance reduces from 1.2 (c) to 1.1 (d) showing the initiation of polymerization, thus establishing the mechanism of complex initiation. The polymerization through complex medium is evident by sharp change in absorbance from 1.3 (b) to 0.5 (e) in Figure 5. In addition, the complex formation and initiation of polymerization are also evidenced from the change in $\mathrm{Co}\left(\mathrm{NO}_{3}\right)_{2}$ pink color to deep pink with en and the gradual fading of the pink color with reaction time by the addition of monomer and initiator. The high-conversion values with $\left[\mathrm{Co}(\mathrm{III})(\mathrm{en})_{2}\left(\mathrm{NO}_{2}\right)_{2}\right] \mathrm{NO}_{3}$ complex may be due to the high rate production of initiating radicals generated by the heterolysis of the initiator bound by a complex of $\left[\mathrm{Co}(\mathrm{III})(\mathrm{en})_{2}\left(\mathrm{NO}_{2}\right)_{2}\right] \mathrm{NO}_{3}$ where the internal

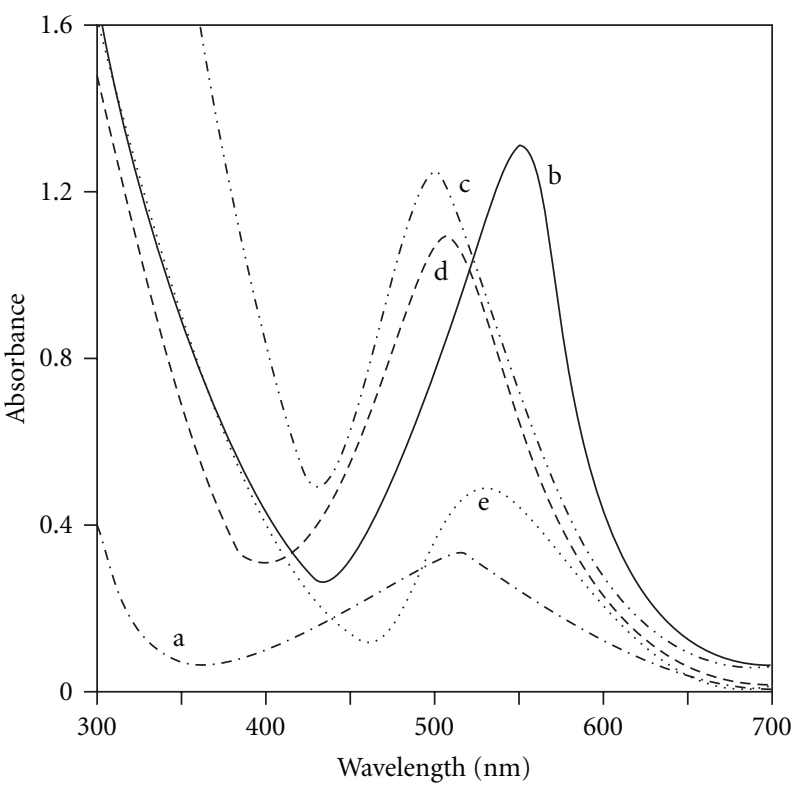

FIgURE 5: UV-visible spectra of (a) $\mathrm{Co}(\mathrm{II})\left(\mathrm{NO}_{2}\right)_{2}$, (b) $\left[\mathrm{Co}(\mathrm{III})(\mathrm{en})_{2}\right.$. $\left.\left(\mathrm{NO}_{2}\right)_{2}\right] \mathrm{NO}_{3}$, (c) $\left[\mathrm{Co}(\mathrm{III})(\mathrm{en})_{2}\left(\mathrm{NO}_{2}\right)_{2}\right] \mathrm{NO}_{3}+\mathrm{AN}$, (d) $[\mathrm{Co}(\mathrm{III})$. $\left.(\mathrm{en})_{2}\left(\mathrm{NO}_{2}\right)_{2}\right] \mathrm{NO}_{3}+\mathrm{AN}+\mathrm{APS}$ before reaction, and (e) $\left[\mathrm{Co}(\mathrm{III})(\mathrm{en})_{2}\left(\mathrm{NO}_{2}\right)_{2}\right] \mathrm{NO}_{3}+\mathrm{AN}+\mathrm{APS}$ after reaction.

energy is transferred to the monomer. The new nonconventional complex initiated system leads to stabilizing the emulsion latex to a high conversion in the absence of an added emulsifier.

It was found that the conversion and the $R_{p}$ were strongly affected by the monomer, initiator, and complex concentration and also by the reaction time. The detailed kinetics is discussed as per our previous article [38] and is expressed in rate law.

3.7. Variation of Time. From Table 1, the variation of conversion with reaction is keeping the concentrations of $\mathrm{AN}, \mathrm{APS}$, and $\left[\mathrm{Co}(\mathrm{III})(\mathrm{en})_{2}\left(\mathrm{NO}_{2}\right)_{2}\right] \mathrm{NO}_{3}$ constant at $2,10 \times$ $10^{-3}$ and $10 \times 10^{-3} \mathrm{moL} \mathrm{dm}^{-3}$, respectively. It was found that the reaction showed a dead-end polymerization tendency, that is, the initiation activity of the initiator is high at initial period and, hence, after $240 \mathrm{sec}$, it increases at a comparatively slow rate, where in case of traditional heating more time was required, that is, $3 \mathrm{~h}$ for production with less conversion $\%$ as compared with microwave irradiation. 
3.7.1. Chain Initiation by Co Complex

$$
\begin{gathered}
\mathrm{Co}(\mathrm{II})+2 \mathrm{en} \stackrel{\beta_{1}}{\rightleftharpoons} \operatorname{Complex}(\mathrm{I}) \quad(\text { Scheme } 1(\mathrm{a})) \\
\text { Complex (I) }+3 \mathrm{AN} \underset{k_{i}}{\stackrel{\beta_{2}}{\rightleftharpoons}} \text { Complex (II) } \quad(\text { Scheme l(b)) } \\
\text { Complex (II) }+\mathrm{S}_{2} \mathrm{O}_{8}{ }^{-2} \rightleftharpoons \mathrm{R}^{\cdot} \mathrm{M}_{1} \quad\left(\mathrm{R}^{\cdot}=\mathrm{S}_{4}{ }^{-\cdot}, \mathrm{M}_{1}=\mathrm{AN}\right)
\end{gathered}
$$

The above complexation mechanism is explained earlier on the basis of the spectral data and Scheme 1(a) and (b).

\subsubsection{Propagation}

$$
\begin{gathered}
\mathrm{R}^{\cdot} \mathrm{M}_{1}+\mathrm{M} \stackrel{k_{\mu}}{\longrightarrow} \mathrm{RM}_{2} \\
\vdots \quad \vdots \\
\mathrm{RM}_{n \cdot 1} \mathrm{M} \stackrel{k_{\beta}}{\longrightarrow} \mathrm{RM}_{n}
\end{gathered}
$$

\subsubsection{Termination}

$$
\begin{aligned}
& \mathrm{RM}_{n}^{\cdot}+\mathrm{RM}_{m}^{\cdot} \stackrel{k_{11}}{\longrightarrow} \text { Polymer } \\
& \mathrm{RM}_{n}^{\cdot}+\mathrm{Co}(\mathrm{III})-\text { Complex } \\
& \quad \stackrel{k_{\mathrm{c} 2}}{\longrightarrow} \text { Polymer }+\mathrm{Co}(\mathrm{II})-\text { Complex }+\mathrm{H}^{+}
\end{aligned}
$$

From Table 1, applying steady state principle and assuming mutual termination, the rate of expression is observed as follows:

$$
R_{p} \propto[\mathrm{Co}(\mathrm{III})]^{0.43}[\mathrm{APS}]^{0.33}[\mathrm{AN}]^{0.77}
$$

\subsection{Water Absorbency}

3.8.1. Effect of (Monomer). The effect of variation in monomer concentration on water absorbency of the nanocomposite showed very interesting results (Table 1). It was observed that for an increase in monomer concentration up to $2.27 \mathrm{moL} \cdot \mathrm{dm}^{-3}$, the water absorbency was increased from 38-87, and, thereafter, it decreased. This might be attributed to the fact that, on increasing the monomer concentration beyond a certain value, the hydrophobic character of PAN prevails over the induction of hydrophilic character to the polymer matrix by the exfoliated clay in it. To explain more clearly, within the above specified limits of (monomer), the water absorbency was increased following a better exfoliation of clay because the available

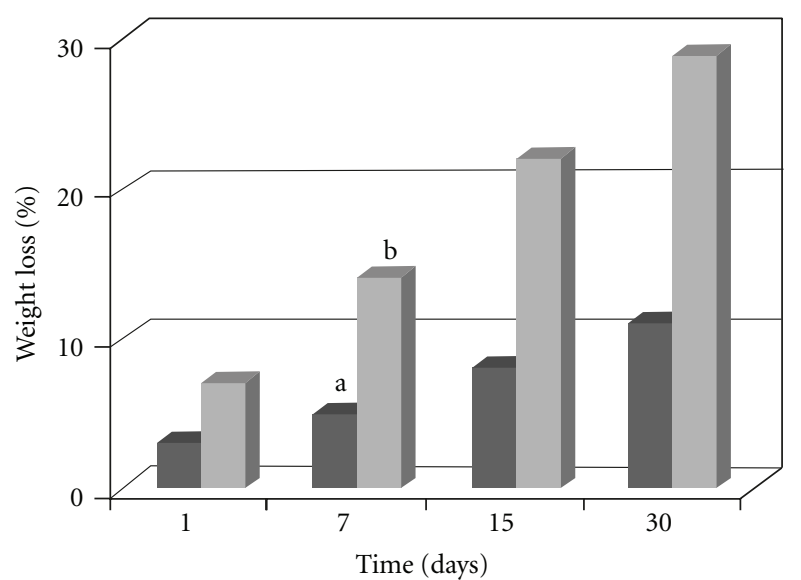

FIGURE 6: Biodegradation by activated sludge of (a) PAN, (b) PAN/MMT ( $5 \% \mathrm{w} / \mathrm{v})$ on time versus weight loss.

area in PAN matrix within these limits is just sufficient as required for a better exfoliation. However, with a further increase in the (monomer) up to 4.55 , although the available area required for exfoliation of clay was increased but the hydrophobicity of PAN matrix predominated any further increase in the water absorbency due to its comparatively high concentration in comparison to (MMT).

3.8.2. Effect of (Initiator). The effect of initiator concentration was studied and presented in Table 1 . The swelling amount was found to increase with an increase in APS concentration from $0.5 \times 10^{-2}$ to $2 \times 10^{-2} \mathrm{moL} \cdot \mathrm{dm}^{-3}$ and then decreased slowly due to increase in number of radicals produced as the concentration of APS increased. The increase in the production of radicals at higher initiator concentration increased the rate of polymerization, thereby lessening the crosslinking density or net-like structure of the MMT inside the PAN matrix, and this factor is responsible for the decrease in the swelling capacity of the polymer.

3.8.3. Effect of $\left[\left[\mathrm{Co}(\mathrm{III})(\mathrm{en})_{2}\left(\mathrm{NO}_{2}\right)_{2}\right] \mathrm{NO}_{3}\right]$. As reported in our earlier publications, here also the synthesis of the nanocomposite was carried out in the presence of a new complex to catalyze the reaction as well as to avoid the use of any added emulsifier. Accordingly, the synthesis of the nanocomposite was carried out under different $\left[\mathrm{Co}(\mathrm{III})(\mathrm{en})_{2}\left(\mathrm{NO}_{2}\right)_{2}\right] \mathrm{NO}_{3}$ concentrations; however, for concentration $2 \times 10^{-2} \mathrm{moL} \mathrm{dm}^{-3}$, the resulting nanocomposite sample recorded highest water absorbency, because, at this concentration, the complex was effective in catalyzing the polymerization reaction as well as in decreasing the particle size to nano order. Thereafter, the high concentration of the complex retarded the rate of polymerization and also decreased the $\%$ conversion following which the exfoliation of clay inside the PAN matrix was less due to less available area of the polymer matrix thereby decreasing the porous nature of the matrix and hence water absorbency. To add with, on the reduction of the particle size, the porous nature 


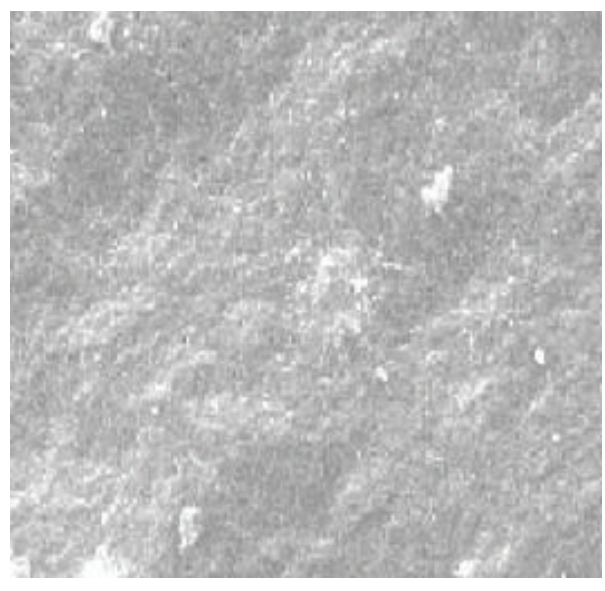

(a)

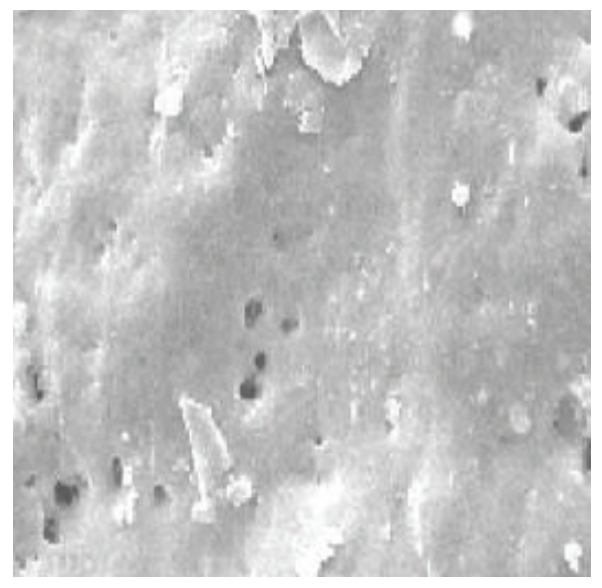

(b)

FIGURE 7: SEM of PAN/MMT nanocomposites (a) before and (b) after 30 days biodegradation.

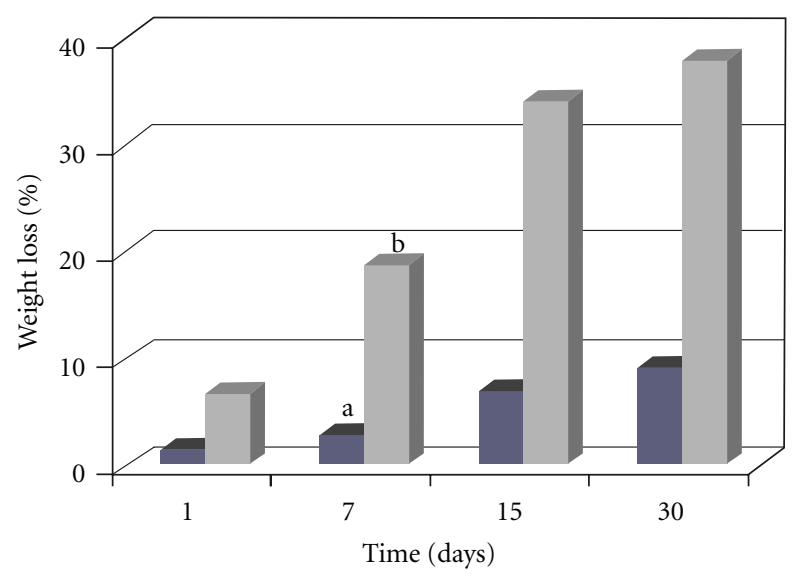

Figure 8: Biodegradation by bacteria (B. cereus) of (a) PAN, (b) $\mathrm{PAN} / \mathrm{MMT}(5 \% \mathrm{w} / \mathrm{v})$ on time versus weight loss.

of the matrix was increased to an extent of having constant water absorbency.

3.8.4. Effect of (MMT). The water absorbency was found to increase with MMT concentrations 1.25 to $5 \mathrm{moL} \cdot \mathrm{dm}^{-3}$ and then decreased as shown in Table 1. This can be explained on the basis of exfoliation of hydrophilic silicate layers inside hydrophobic PAN matrix making more room for water molecules. With higher silicate concentration, the arrangement of silicate layers inside the matrix increased the hydrophobicity of the polymer nanocomposite since the degree of exfoliation of clay layers inside PAN matrix might be suppressed due to a comparatively less available area of the PAN matrix as required by a higher concentration of clay for a better exfoliation. As a result, the porous nature of the matrix was decreased thereby increasing hydrophobicity of the nanocomposite or decreasing its water absorbency

3.9. Biodegradation in Activated Sludge and Culture Media. From the comparative biodegradation study of PAN,

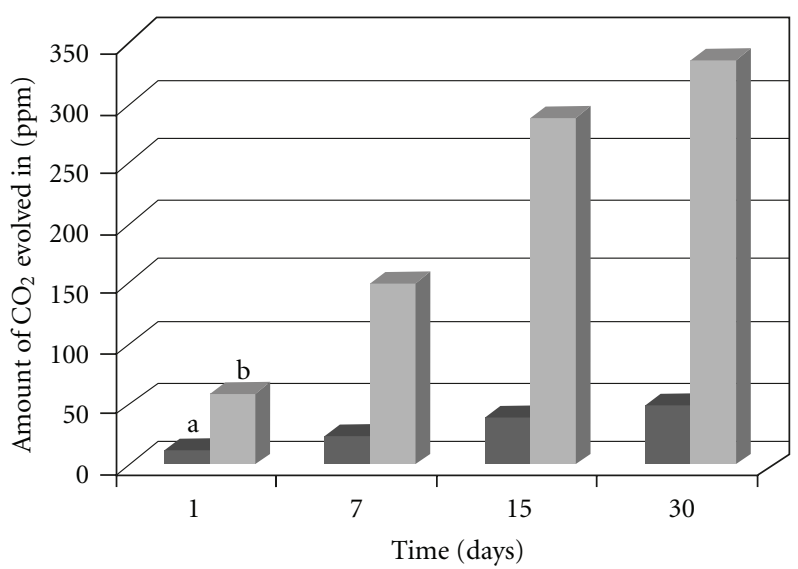

Figure 9: Biodegradation by bacteria (B. cereus) of (a) PAN, (b) PAN/MMT (5\%w/v) on time versus amount of $\mathrm{CO}_{2}$ evolved.

PAN/MMT, it was found that PAN showed low accelerated rate of degradation by weight loss initially, but after 21 days, it was slowed down. The PAN/MMT nanocomposite showed tremendous rate of degradation in activated sludge as shown in Figure 6 since it contains different varieties of microorganisms which can rapidly degrade the sample as confirmed by SEM Figure 7.

The weight loss data in Figure 8 revealed that PAN/MMT nanocomposite degraded under the influence of $B$. cereus at a faster rate than PAN. The degradation value was least in case of PAN due to its hydrophobic nature. Due to the hydrophilic nature of MMT, the water absorbency and the growth of microorganisms have been increased in the PAN/MMT nanocomposite. The rate of water absorbency of PAN and PAN/MMT nanocomposites was given in Table 1 to justify the biodegradability data.

Again, the rate of degradation was also measured by calculating the amount of $\mathrm{CO}_{2}$ evolved from the cultured medium at interval period of times. The results in Figure 9 showed similar trend of degradation exhibiting 
more biodegradability of the nanocomposite than the other samples. On comparison of both weight-loss method and the $\mathrm{CO}_{2}$ release method for the study of degradation of the nanocomposite, it was inferred that the rate of degradation of PAN/MMT nanocomposite was equivalent in both methods, and it was further concluded that the nanocomposite was biodegradable in nature. Thus the deviation in the degrading behavior of $B$. cereus might be due to the difference in the carbon sources used by the bacteria for their growth.

\section{Conclusion}

PAN/MMT nanocomposites are prepared by using a Co(III) complex in a domestic microwave oven. In microwave oven, the polymerization took place very fast and consumed very less time. The fast polymerization reactions occurred by fast decomposition of initiator due to the complex. The formation of nanocomposites was characterized by FTIR, further confirmed from XRD and TEM. Due to the bond between PAN and MMT, the thermal stability of PAN/ MMT nanocomposite is increased. The mechanical properties of PAN/MMT nanocomposites, UV-visible spectra of complex and the mechanism of polymerization were studied. The biodegradation of the samples was also studied for their better commercialization.

\section{References}

[1] H. M. Jeong, B. C. Kim, and E. H. Kim, "Structure and properties of EVOH/organoclay nanocomposites," Journal of Materials Science, vol. 40, no. 14, pp. 3783-3787, 2005.

[2] H. Ishida, S. Campbell, and J. Blackwell, "General approach to nanocomposite preparation," Chemistry of Materials, vol. 12, no. 5, pp. 1260-1267, 2000.

[3] Z. Wang and T. J. Pinnavaia, "Hybrid organic-inorganic nanocomposites: exfoliation of magadiite nanolayers in an elastomeric epoxy polymer," Chemistry of Materials, vol. 10, no. 7, pp. 1820-1826, 1998.

[4] S. Wang, Y. Hu, L. Song, Z. Wang, Z. Chen, and W. Fan, "Preparation and thermal properties of ABS/montmorillonite nanocomposite," Polymer Degradation and Stability, vol. 77, no. 3, pp. 423-426, 2002.

[5] J. W. Gilman, "Flammability and thermal stability studies of polymer layered-silicate (clay) nanocomposites," Applied Clay Science, vol. 15, no. 1-2, pp. 31-49, 1999.

[6] P. K. Sahoo and R. Samal, "Fire retardancy and biodegradability of poly(methyl methacrylate)/montmorillonite nanocomposite," Polymer Degradation and Stability, vol. 92, no. 9, pp. 1700-1707, 2007.

[7] M. Biswas and S. S. Ray, "Recent progress in synthesis and evaluation of polymer-montmorillonite nanocomposites," Advances in Polymer Science, vol. 155, pp. 167-221, 2001.

[8] E. P. Giannelis, "Polymer-layered silicate nanocomposites: synthesis, properties and applications," Applied Organometallic Chemistry, vol. 12, no. 10-11, pp. 675-680, 1998.

[9] R. Xu, E. Manias, A. J. Snyder, and J. Runt, "New biomédical poly(urethane urea)-layered silicate nanocomposites," Macromolecules, vol. 34, no. 2, pp. 337-339, 2001.

[10] S. Bourbigot, M. Le Bras, F. Dabrowski, J. W. Gilman, and T. Kashiwagi, "PA-6 clay nanocomposite hybrid as char forming agent in intumescent formulations," Fire and Materials, vol. 24, no. 4, pp. 201-208, 2000.

[11] S. S. Ray, K. Yamada, M. Okamoto, and K. Ueda, "Polylactidelayered silicate nanocomposite: a novel biodegradable material," Nano Letters, vol. 2, no. 10, pp. 1093-1096, 2002.

[12] P. K. Sahoo and R. Mohapatra, "Synthesis and kinetic studies of PMMA nanoparticles by non-conventionally initiated emulsion polymerization," European Polymer Journal, vol. 39, no. 9, pp. 1839-1846, 2003.

[13] V. Kuppa and E. Manias, "Computer simulation of PEO/ layered-silicate nanocomposites: 2. Lithium dynamics in PEO/Li montmorillonite intercalates," Chemistry of Materials, vol. 14, no. 5, pp. 2171-2175, 2002.

[14] X. Fang, C. D. Simone, E. Vaccaro, S. J. Huang, and D. A. Scola, "Ring-opening polymerization of $\varepsilon$-caprolactam and $\varepsilon$ caprolactone via microwave irradiation," Journal of Polymer Science A, vol. 40, no. 14, pp. 2264-2275, 2002.

[15] J. Jacob, L. H. L. Chia, and F. Y. C. Boey, "Microwave polymerization of poly(methyl acrylate): conversion studies at variable power," Journal of Applied Polymer Science, vol. 63, no. 6, pp. 787-797, 1997.

[16] M. A. Stuchly and S. S. Stuchly, "Industrial, scientific, medical and domestic applications of microwaves," IEE Proceedings A, vol. 130, no. 8, pp. 467-503, 1983.

[17] R. Correa, G. Gonzalez, and V. Dougar, "Emulsion polymerization in a microwave reactor," Polymer, vol. 39, no. 6-7, pp. 1471-1474, 1998.

[18] L. H. L. Chia, J. Jacob, and F. Boey, "Radiation curing of poly-methyl-methacrylate using a variable power microwave source," The Journal of Materials Processing Technology, vol. 48, no. 1-4, pp. 445-449, 1995.

[19] J. Jacob, L. H. L. Chia, and F. Y. C. Boey, "Comparative study of methyl methacrylate cure by microwave radiation versus thermal energy," Polymer Testing, vol. 14, no. 4, pp. 343-354, 1995.

[20] M. A. Paul, M. Alexandre, P. Degee, C. Henrist, A. Rulmont, and P. Dubois, "New nanocomposite materials based on plasticized poly(l-lactide) and organo-modified montmorillonites: thermal and morphological study," Polymer, vol. 44, pp. 443-450, 2003.

[21] S. S. Ray, K. Yamada, M. Okamoto, and K. Ueda, "Crystallization behaviour and morphology of biodegradable polylactide/layered silicate nanocomposite," Polymer, vol. 44, pp. 857866, 2003.

[22] S. H. Park, S. T. Lim, T. K. Shin, H. J. Choi, and M. S. Jhon, "Viscoelasticity of biodegradable polymer blends of poly(3hydroxybutyrate) and poly(ethylene oxide)," Polymer, vol. 42, no. 13, pp. 5737-5742, 2001.

[23] B. Lepoittevin, N. Pantoustier, M. Alexandre, C. Calberg, R. Jérôme, and P. Dubois, "Polyester layered silicate nanohybrids by controlled grafting polymerization," Journal of Materials Chemistry, vol. 12, no. 12, pp. 3528-3532, 2002.

[24] R. K. Bharadwaj, A. R. Mehrabi, C. Hamilton et al., "Structure-property relationships in cross-linked polyesterclay nanocomposites," Polymer, vol. 43, no. 13, pp. 3699-3705, 2002.

[25] P. K. Sahoo, R. Samal, S. K. Swain, and P. K. Rana, "Synthesis of poly(butyl acrylate)/sodium silicate nanocomposite fire retardant," European Polymer Journal, vol. 44, no. 11, pp. 3522-3528, 2008.

[26] P. K. Sahoo, S. P. Bhattacharjee, and R. K. Samal, "Influence of $\mathrm{Cu}(\mathrm{II}) /$ salicylaldehyde couple on potassium monopersulphate 
decomposition and acrylonitrile polymerization in solution," European Polymer Journal, vol. 21, no. 5, pp. 499-503, 1985.

[27] K. Mohana Raju and M. Padmanabha Raju, "Synthesis of novel superabsorbing copolymers for agricultural and horticultural applications," Polymer International, vol. 50, no. 8, pp. 946-951, 2001.

[28] T. W. Federle, M. A. Barlaz, C. A. Pettigrew et al., "Anaerobic biodegradation of aliphatic polyesters: poly(3-hydroxybutyrate-co-3-hydroxyoctanoate) and poly(E-caprolactone)," Biomacromolecules, vol. 3, no. 4, pp. 813-822, 2002.

[29] O. P. Vermani and A. K. Narula, Applied Chemistry (Theory and Practice), Wiley Eastern, 1989.

[30] P. K. Sahoo, M. Dey, and S. K. Swain, "Emulsifier-free emulsion polymerization of acrylonitrile: effect of in situ developed $\mathrm{Cu}$ (II)/glycine chelate complex initiated by monopersulfate," Journal of Applied Polymer Science, vol. 74, no. 12, pp. 27852790, 1999.

[31] P. Maiti, P. H. Nam, M. Okamoto, N. Hasegawa, and A. Usuki, "Influence of crystallization on intercalation, morphology, and mechanical properties of polypropylene/clay nanocomposites," Macromolecules, vol. 35, no. 6, pp. 2042-2049, 2002.

[32] O. Becker, Y.-B. Cheng, R. J. Varley, and G. P. Simon, "Layered silicate nanocomposites based on various highfunctionality epoxy resins: the influence of cure temperature on morphology, mechanical properties, and free volume," Macromolecules, vol. 36, no. 5, pp. 1616-1625, 2003.

[33] C. M. L. Preston, G. Amarasinghe, J. L. Hopewell, R. A. Shanks, and Z. Mathys, "Evaluation of polar ethylene copolymers as fire retardant nanocomposite matrices," Polymer Degradation and Stability, vol. 84, no. 3, pp. 533-544, 2004.

[34] A. Ambre, R. Jagtap, and B. Dewangan, "ABS nanocomposites containing modified clay," Journal of Reinforced Plastics and Composites, vol. 28, no. 3, pp. 343-352, 2009.

[35] K. H. Wang, M. H. Choi, C. M. Koo et al., "Morphology and physical properties of polyethylene/silicate nanocomposite prepared by melt intercalation," Journal of Polymer Science B, vol. 40, no. 14, pp. 1454-1463, 2002.

[36] S. K. Swain and A. I. Isayev, "Effect of ultrasound on HDPE/clay nanocomposites: rheology, structure and properties," Polymer, vol. 48, no. 1, pp. 281-289, 2007.

[37] Vogel's Textbook of Quantitative Inorganic Analysis, ELBS and Longman, 4th edition, 1978.

[38] T. Biswal, R. Samal, and P. K. Sahoo, "Complex-mediated microwave-assisted synthesis of polyacrylonitrile nanoparticles," Nanotechnology, Science and Applications, vol. 3, no. 1, pp. 77-83, 2010. 

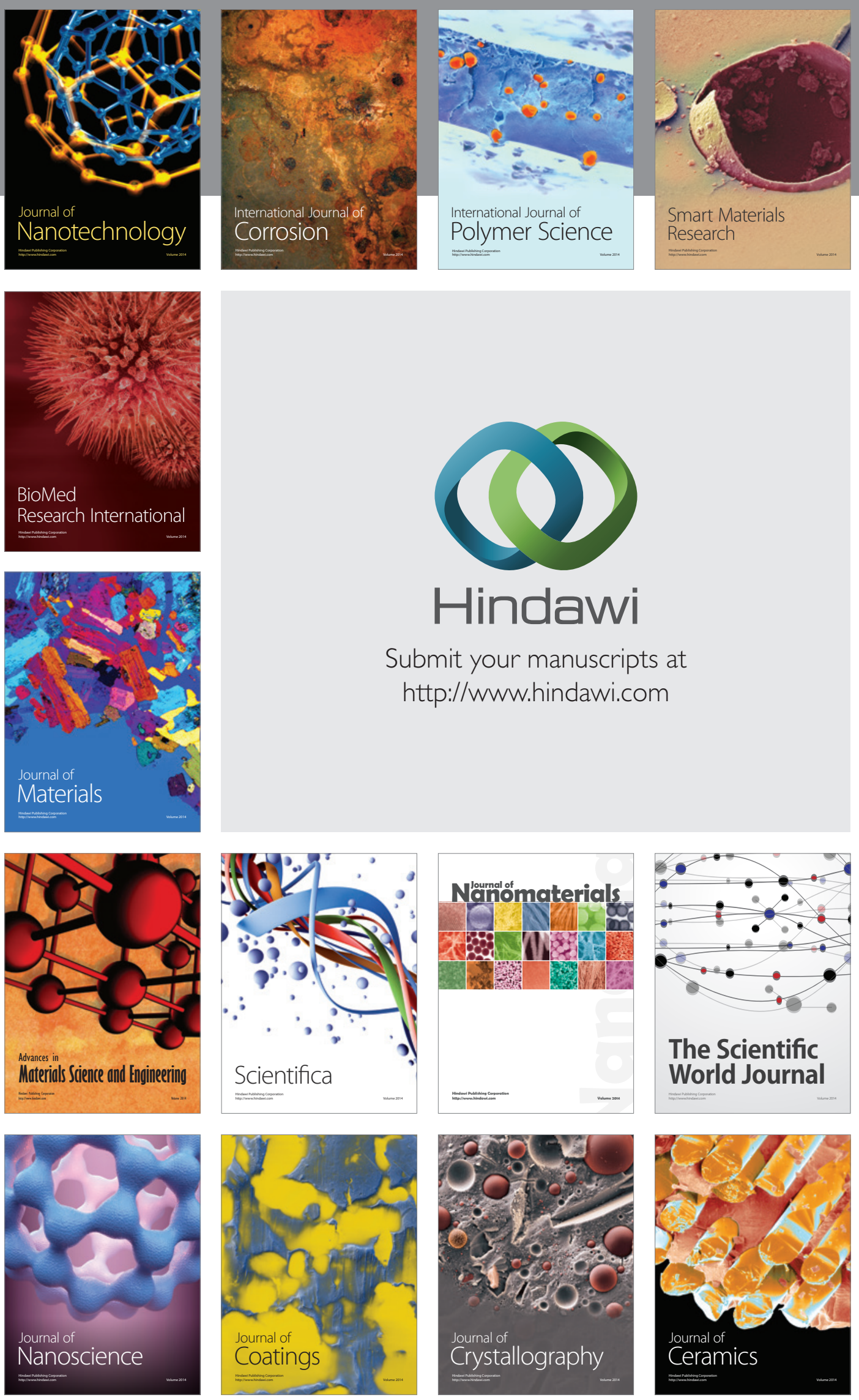

The Scientific World Journal

Submit your manuscripts at

http://www.hindawi.com

\section{World Journal}

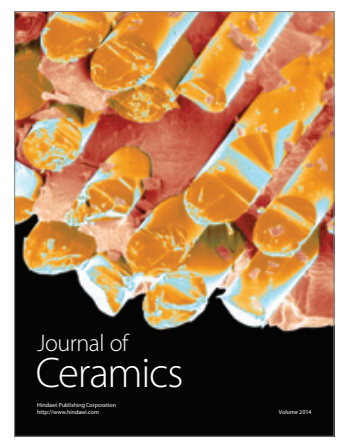

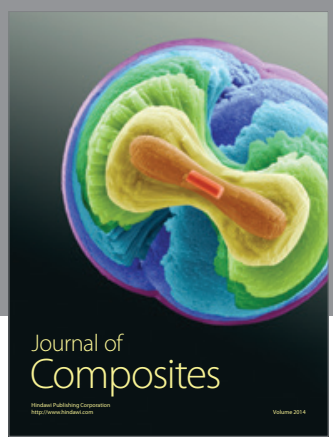
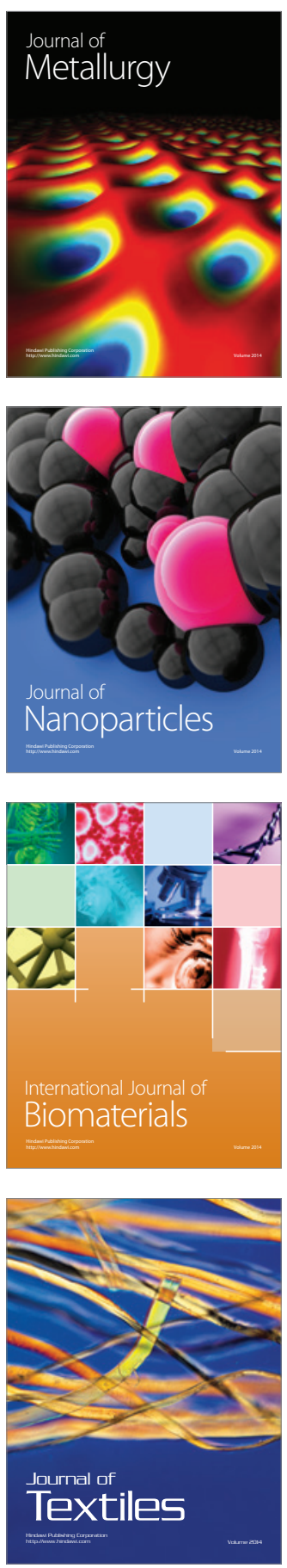